\title{
Characterization of Aphanomyces invadans by electrophoretic and Western blot analysis
}

\author{
J. H. Lilley*, K. D. Thompson, A. Adams \\ Institute of Aquaculture, University of Stirling, Stirling FK9 4LA, Scotland, UK
}

\begin{abstract}
Fungal mycelium extracts were subjected to gel electrophoresis and Western blot analysis with various lectins and polyclonal antisera. These techniques succeeded in identifying bands specific to pathogenic Aphanomyces strains from fish affected by epizootic ulcerative syndrome, redspot disease and mycotic granulomatosis when compared to various other Oomycete fungi. It is concluded that these isolates are conspecific under the name Aphanomyces invadans (previously described by Willoughby et al. 1995 ( $\mathrm{J}$ Fish Dis 18:273-275) as A. invaderis] and the various protein and carbohydrate bands identified may provide useful species-specific taxonomic markers. Besides the distinctive band profiles for $A$. invadans on gels subjected to various stains, lectins revealed a specific $45 \mathrm{kDa}$ component, and polyclonal antisera highlighted an immunogenic $10 \mathrm{kDa}$ band. Peroxidase and fluorescein conjugated antisera provided an effective diagnostic tool for identifying hyphae in infected fish tissue.
\end{abstract}

KEY WORDS: Epizootic Ulcerative Syndrome - Fungus - Aphanomyces invadans SDS-PAGE - Western blot analysis - Lectins - Immunohistochemistry

\section{INTRODUCTION}

Aphanomyces invadans is the main aetiological component of a serious disease of Asian freshwater and estuarine fish stocks known as epizootic ulcerative syndrome (EUS). It was described by Willoughby et al. (1995) under the name Aphanomyces invaderis, but is now listed in the Index of Fungi (1997) as $A$. invadans. Recent work has shown that this fungus appears to be pathogenically and culturally identical to similar Aphanomyces isolates from fish suffering from redspot disease (RSD) in Australia and mycotic granulomatosis (MG) in Japan (Lilley \& Roberts 1997). Strains from the latter disease, however, have been generally referred to as Aphanomyces piscicida (Hatai 1980). Previous sodium dodecyl sulphate polyacrylamide gel electrophoresis (SDS-PAGE) by Thompson et al. (1997) and Callinan et al. (1995) reported similarities between the SDS-PAGE profiles of Aphanomyces sp. isolated from fish infected with EUS, RSD and MG. Western blot analysis with immunized snakehead fish Channa striata sera supported this finding (Thompson et al. 1997).

·E-mail: jhl1@stirling.ac.uk
Other studies have employed protein electrophoresis as a means of establishing interspecific and intraspecific relationships between Oomycete fungi (Chen et al. 1991, Latorre et al. 1995). In the present study, a wide range of EUS, RSD and MG isolates were compared by SDS-PAGE, as well as a variety of Oomycete saprophytes and fungi from other diseases of aquatic animals, namely ulcerative mycosis (UM) (Dykstra et al. 1989), crayfish plague (Alderman 1993) and saprolegniasis (Bruno \& Stamps 1987). An attempt was made to characterize strain-specific bands using various stains, lectins and polyclonal antibodies.

\section{MATERIALS AND METHODS}

Fungal isolates. A list of the fungi used in the present study is given in Table 1 and further details can be found in Lilley \& Roberts (1997).

Preparation of fungal extracts. To obtain proteinrich fungal extracts, $45 \mathrm{ml}$ zoospore suspensions were produced in Petri dishes as described by Willoughby \& Roberts (1994) and added to an equal volume of double strength glucose-peptone-yeast (GPY) broth (Willoughby \& Roberts 1994). Germlings were allowed 
Table 1. Fungal strains used in this study

\begin{tabular}{|ll}
\hline Isolates & Description \\
\hline TA1, RF6, RF8, S1PA, G2PA, & Aphanomyces invadans from EUS-affected fish in Thailand \\
PA4, PA5, PA7, PA10 & A. invadans from EUS-affected fish in Bangladesh \\
BH, BS & A. invadans from an EUS-affected fish in Indonesia \\
$36 / 1 P$ & A. invadans from EUS-affected fish in the Philippines \\
10D, 33P & Aphanomyces sp. from RSD-affected fish in Australia \\
3P, 4P, 10P, 24P & Aphanomyces piscicida from a MG-affected fish in Japan \\
NJM9030 & Aphanomyces sp. from an UM-affected fish in the USA \\
84-1240 (= ATCC 62427) & Aphanomyces astaci from plagued crayfish in the UK \\
FDL457, FDL458 & Aphanomyces sp. saprophytes from EUS-affected fish in Thailand \\
TF5, TF33, TF41, F3SA, SSA, SA11 & Aphanomyces sp. saprophyte from a diseased turtle in Thailand \\
T1SA & Aphanomyces sp. saprophytes from EUS-affected pond water in Thailand \\
WSA & Aphanomyces laevis saprophytes from EUS-affected pond water in Thailand \\
ASEAN1 & Achlya diffusa saprophyte from EUS-affected pond water in Thailand \\
W2BAC & Achlya sp. saprophytes from EUS-affected fish in Thailand \\
S2AC, AC2 & Saprolegnia sp. saprophytes from EUS-affected fish in Thailand \\
TF29, TF31 & Saprolegnia australis saprophyte from a fish in the UK \\
S.AUST & Saprolegnia ferax saprophyte from lake water in the UK \\
P32 & Saprolegnia parasitica from a saprolegniasis-affected fish in the UK \\
TP41 (=ATCC 42062) & \\
\hline
\end{tabular}

to develop for 1 to $3 \mathrm{~d}$ at $22^{\circ} \mathrm{C}$, depending on the growth rate of the isolate, so that thin mycelial mats formed on the bottom of each Petri dish. Growth medium was decanted and the samples washed once in $500 \mathrm{ml}$ sterile distilled water. Samples were harvested on sterile Whatman 541 filter paper and excess water removed using dry sterile filter paper. Fungal mats were ground in liquid nitrogen using a pestle and mortar. The resulting powder was then homogenized in $1 \mathrm{ml}$ Wood's (1988) extraction buffer $(85 \mathrm{mM}$ Tris $\mathrm{HCl}_{1} 1 \mathrm{mM} \mathrm{MgCl}, 1 \mathrm{mM}$ EDTA, $10 \mathrm{mM} \mathrm{KCl}, 0.198 \mathrm{~g} \mathrm{l}^{-1}$ ascorbic acid and $1 \mathrm{~g} \mathrm{l}^{-1}$ glycerol at $\mathrm{pH}$ 7.5) with the addition of $5 \mu \mathrm{M}$ phenylmethylsulphonylfluoride (PMSF) (Sigma). The homogenate was centrifuged twice at $13000 \times g$ for $5 \mathrm{~min}$ and the protein concentrations of the extracts were estimated by ultraspectrophotometric readings at $\mathrm{OD}_{280}$ (OD: optical density). These were adjusted to $5 \mathrm{mg} \mathrm{ml}^{-1}$ with sample buffer and the extracts were frozen at $-70^{\circ} \mathrm{C}$. Prior to adding sample buffer, a $1.00 \mu \mathrm{l}$ aliquot was taken of each extract and stored at $-70^{\circ} \mathrm{C}$ for subsequent protein digestion. This involved incubating the aliquots with $100 \mu \mathrm{l}$ of a $10 \mu \mathrm{l}$ $\mathrm{ml}^{-1}$ solution of proteinase $\mathrm{K}$ (Sigma) for $1 \mathrm{~h}$ at $60^{\circ} \mathrm{C}$ before diluting in sample buffer.

Preparation of extracellular products (ECP). Media $(500 \mathrm{ml}$ GPY) in which the fungi had been cultured were collected, placed in dialysis tubing with a molecular weight cutoff of $10 \mathrm{kDa}$ (Fisons) and concentrated using polyethylene glycerol ( $8 \mathrm{kDa}$, Sigma). Concentrates were dialyzed using 3 changes of $2 \mathrm{l}$ phosphate buffered saline (PBS: $0.02 \mathrm{M} \mathrm{NaH}_{2} \mathrm{PO}_{4} \cdot 2 \mathrm{H}_{2} \mathrm{O}, 0.02 \mathrm{M}$ $\mathrm{Na}_{2} \mathrm{HPO}_{4} \cdot 2 \mathrm{H}_{2} \mathrm{O}, 0.15 \mathrm{M} \mathrm{NaCl}, \mathrm{pH} 7.2$ ) over 24 h at $4^{\circ} \mathrm{C}$.
SDS-PAGE analysis. SDS-PAGE was performed by the method of Laemmli (1970) using precast acrylamide separating gels $(4-20 \%)$ (BioRad). The gels were subjected to electrophoresis for $45 \mathrm{~min}$ at $200 \mathrm{~V}$, then stained with either $0.1 \%(w / v)$ Coomassie Brilliant Blue R (Sigma), silver stain (BioRad) or Schiff's reagent (Merck).

Electroelution of $\mathbf{1 0} \mathbf{k D a}$ band. An Aphanomyces invadans-specific band (from isolate PA7) of molecular weight $10 \mathrm{kDa}$ was excised from a $12 \%$ (w/v) polyacrylamide slab gel and electroeluted using a Hoefer electroeluter at $100 \mathrm{~V}$ for $1 \mathrm{~h}$ according to manufacturer's specifications.

Immunization schedule. Three New Zealand White rabbits were immunized with mycelium extracts from either (a) a saprophytic Aphanomyces isolate F3SA, (b) A. invadans PA7 or (c) the electroeluted band from PA7. The extracts (300 $\mu$ g protein) were mixed 1:1 with Freund's complete adjuvant (Sigma) and $1.5 \mathrm{ml}$ was deluvered subcutaneously (SC) at 2 sites. Each rabbit was given 2 further $\mathrm{SC}$ booster injections of fungal extract in Freund's incomplete adjuvant 4 and 8 wk later. A final injection of $1 \mathrm{ml}$ fungal extract in sterile saline was given intravenously in Week 1.2. The rabbits were bled out by cardiac puncture $10 \mathrm{~d}$ later.

Western blot analysis. The polyclonal antisera were used to screen each isolate for antigenic bands by Western blot analysis. Samples were applied to each lane and subjected to electrophoresis as described above. The samples were transferred from the gel to a sheet of nitrocellulose membrane by a wet blotting system (Hoefer) at $50 \mathrm{~V}$ for $1 \mathrm{~h}$. Following transfer, the 
nitrocellulose membrane was washed with 2 changes of high salt wash buffer (HSW: $0.02 \mathrm{M}$ Tris, $0.5 \mathrm{M}$ $\mathrm{NaCl}, 0.1 \%$ Tween $20,0.01 \%$ methiolate, $\mathrm{pH} 7.8$ ) and blocked for 2 h with $1.0 \%(\mathrm{w} / \mathrm{v})$ bovine serum albumin in distilled water. The membrane was then washed twice in HSW and antisera (diluted $1 / 100$ in PBS) were applied to the nitrocellulose membrane and incubated for $1 \mathrm{~h}$ at $4^{\circ} \mathrm{C}$. After 2 washes in HSW, goat anti-rabbit IgG-Horseradish Peroxidase (HRP) conjugate [SAPU: Scottish Antibody Production Unit, Carluke, UK; (diluted $1 / 100$ in $0.5 \%(w / v)$ casein in PBS) was applied to the membrane and left for a further hour. Unbound conjugate was removed from the membrane by washing twice in HSW followed by 1 wash with Tris buffered saline (TBS: $10 \mathrm{mM}$ Tris, $0.15 \mathrm{M} \mathrm{NaCl}, \mathrm{pH} 7.5$ ). The blot was developed with 4-chloro-1-naphthol (BioRad) and the reaction stopped with distilled water.

Lectins were used to examine carbohydrate moieties in each of the fungal extracts. For these studies the nitrocellulose membranes were incubated for $1 \mathrm{~h}$ with lectins labelled with biotin (Sigma) (see Table 2) diluted to $20 \mu \mathrm{g} \mathrm{ml}^{-1}$ in low salt wash buffer (LSW: $0.02 \mathrm{M}$ Tris, $0.038 \mathrm{M} \mathrm{NaCl}, 0.05 \%$ Tween $20,0.01 \%$ merthiolate, $\mathrm{pH}$ 7.4) in place of the rabbit polyclonal antisera. The blots were washed and incubated for $1 \mathrm{~h}$ with streptavadin-peroxidase (SAPU) diluted $1 / 100$ in LSW buffer. Finally, the membranes were washed 5 times with HSW buffer and the reaction developed as described above.

Immunohistochemistry (IHC). The technique used was based on the method of Adams \& Marin de Mateo (1994). Fixed blocks of muscle from snakehead fish experimentally infected with Aphanomyces invadans isolate TA1 were embedded in paraffin wax and sectioned at $5 \mu \mathrm{m}$. The tissue sections were dewaxed, encircled with a wax PAP pen (Merck) and fixed for 10 min with methanol containing $10 \% \mathrm{v} / \mathrm{v}$ hydrogen peroxide to bleach endogenous peroxidases. The slides were then washed 3 times with TBS. Normal goat serum diluted in
TBS $(10 \% \mathrm{v} / \mathrm{v})$ was added to the slides which were then incubated for a further $20 \mathrm{~min}$. The serum was poured off, the slides were placed in a moist chamber and each of the 3 rabbit sera ( $1 / 100$ in TBS) were added to the sections for 1 h at $20^{\circ} \mathrm{C}$. Normal rabbit serum was used as a negative control. The slides were washed as above. Goat anti-rabbit-HRP conjugate (1/50 in TBS) was added to the slides for $1 \mathrm{~h}$ and the slides washed as previously described. To visualize the reaction, slides were incubated for $10 \mathrm{~min}$ with 3,3'-diaminobenzidine tetrahydrochloride (DAB) (Sigma) in the presence of hydrogen peroxide $\left(\mathrm{H}_{2} \mathrm{O}_{2}\right]\left[100 \mu\right.$ of $1 \% \mathrm{H}_{2} \mathrm{O}_{2}$ to $0.5 \mathrm{ml}$ (1.5 $\mathrm{mg} \mathrm{ml}^{-1}$ ) DAB and $5 \mathrm{ml}$ TBS). The reaction was stopped by immersing the slides in tap water. The slides were counterstained with haematoxylin for 3 to 4 min then dehydrated and mounted. Microscopically, positive tissue appeared brown in colour.

Indirect fluorescent antibody technique (IFAT). IFAT was carried out on TA1 tissue sections according to Neelam et al. (1995) using $1 / 100$ dilutions of the rabbit antisera. Normal rabbit serum was used as the negative control. A $1 / 100$ dilution of fluorescein isothiocyanate (FITC)-donkey anti-rabbit IgG (SAPU) was used as the secondary antibody.

\section{RESULTS}

All the isolates listed in Table 1 were tested using SDS-PAGE and a selection of isolates was included in Western blot studies but, given the volume of data generated, only selected results are illustrated here.

\section{SDS-PAGE analysis}

Coomassie Brilliant Blue R stained SDS-PAGE gels gave very similar banding patterns for all the EUS, RSD and MG isolates (Fig. 1) and these were distinct

Table 2. Lectins used in this study

\begin{tabular}{|lcl|}
\hline Lectin (origin) & Abbreviation & Carbohydrate specificity \\
\hline Concanavalin A (Canavalia ensiformis) & Con A & Terminal $\alpha$-D-mannosyl and $\alpha$-D-glucosyl residues \\
Wheat germ agglutinin (Triticum vulgaris) & WGA & N-acetyl- $\beta$-D-glucosaminyl residues and \\
Coral tree agglutinin (Erythrina cristagalli) & ECA & -acetyl- $\beta$-D-glucosamine oligomers \\
Horse gram agglutinin (Dolichos biflorus) & HGA & D-galactose and D-galactosides \\
Soybean agglutinin (Glycine max) & GMA & Terminal N-acetyl- $\alpha$-D-galactosaminyl residues \\
(Bandeiraea simpicifolia) & BS-1 & Terminal $\alpha$-D-galactosyl and \\
Tomato agglutinin (Lycopersicon esculentum) & LEA & N-acetyl- $\alpha$-D-galactosaminyl residues \\
Gorse seed agglutinin (Ulex europaeus) & UEA-1 & N-acetyl- $\beta$-D-glucosamine oligomers \\
Peanut agglutinin (Arachis hypoaea) & AHA & D-fucose \\
& & \\
\hline
\end{tabular}




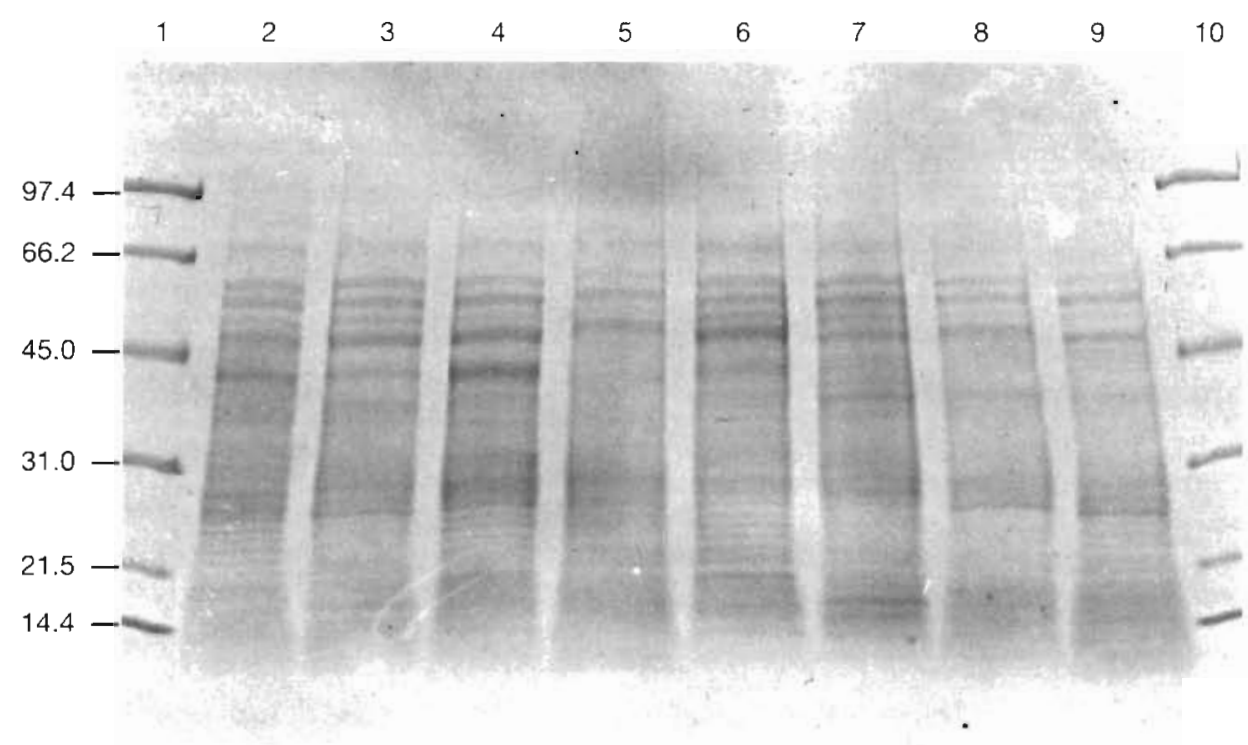

Fig. 1. Coomassie Brilliant Blue $\mathrm{R}$ stained SDS-PAGE gel $(4-20 \%)$ of various isolates of Aphanomyces invadans (Lanes 2 to 7) and RSD-Aphanomyces (Lanes 8 and 9) showing almost identical polypeptide band patterns. Lanes: (1 and 10) BioRad low molecular weight markers; (2) RF6; (3) G2PA; (4) PA7; (5) $\mathrm{BH}_{i}$ (6) 36/1P; (7) 10D; (8) $4 \mathrm{P}$ and (9) $24 \mathrm{P}$ from all other fungi tested. Bands shown by these isolates visualized using Coomassie Brilliant Blue R consistently occurred at 48, 56 and $61 \mathrm{kDa}$. However, banding patterns were generally rather faint, therefore the more sensitive silver stain was used to further highlight bands. Using silver stain, the intensity and number of bands visualized were greater for the EUS, RSD and $\mathrm{MG}$ isolates compared with the other fungi. In order to compare isolates from different gels a pictorial representation of the silver stain bands was constructed (Fig. 2a). Bands specific to all the EUS, RSD and MG isolates were located at approximately 10,84 , 195 and $240 \mathrm{kDa}$. The $10 \mathrm{kDa}$ band was electroeluted, and its presence in the resulting sample was verified using SDS-PAGE (Fig. 2b). This sample was used to prepare the third polyclonal antiserum ( $\alpha$ band). While the bands mentioned above remained constant, molecular weights of other bands were inconsistent when gels were stained with the silver stain reagent, even between different gels run using the same fungal extracts. Silver staining also showed similarities between other fungal isolates, with clear groups being identified among some of the saprophytic Aphanomyces (TF5, TF41, F3SA, SSA and T1SA), 2 of the Achlya isolates (S2AC and AC2) and 2 Saprolegnia isolates (TF29 and TF31).

Silver-stained proteinase K-treated samples and Schiff's-stained gels revealed high levels of the low molecular weight carbohydrate around $10 \mathrm{kDa}$ in Aphanomyces invadans (as shown for PA7 in Fig. 3a, Lanes 1 and 2 respectively) and at approximately 5 and $14 \mathrm{kDa}$ in most of the saprophytic Aphanomyces (as shown for F3SA in Fig. 3b, Lanes 1 and 2). These bands can also be identified on the untreated silver-stained gels (Fig. 2a). Another carbohydrate band of note revealed by Schiff's staining was the $100 \mathrm{kDa}$ band which was apparent on EUS (Fig. 3a, Lane 2), RSD and MG isolates (data not shown) but not on any of the other fungi.

\section{Western blot analysis}

\section{Lectins}

Fig. 3 also shows the bands of PA7 and F3SA recognised by each lectin. The bands described above could not be positively identified by lectin staining studies, although the $100 \mathrm{kDa}$ band visualized using Schiff's stain may equate with a band of similar size revealed by the lectin LEA on EUS, RSD and MG isolates. The relative affinities of each lectin for the fungal carbohydrates varied, as indicated by the time taken for bands to develop in 4-chloro-1-naphthol. This ranged from $10 \mathrm{~s}$ for Con A to $14 \mathrm{~h}$ for LEA.

There was again remarkable consistency between EUS, RSD and MG isolates in terms of the bands revealed by lectin binding on the Western blots. Fig. 4 a illustrates this consistency with regard to HGA. The lectin UEA-1 gave a very similar banding pattern to HGA. Out of the 9 lectins tested, only ECA revealed any differences between Aphanomyces invadans isolates, with 36/1P and 10D showing possible additional bands (Fig. 4b, Lanes 5 and 6). For all the EUS, RSD and $M G$ isolates, a band at approximately $45 \mathrm{kDa}$ was recognised by Con A, ECA, HGA, BS-1, LEA and UEA-1. WGA recognised a region between 33 and $123 \mathrm{kDa}$, producing an area of continuous staining.

For F3SA and a few apparently similar saprophytes, 2 bands were generally recognised at 55 and $90 \mathrm{kDa}$ 


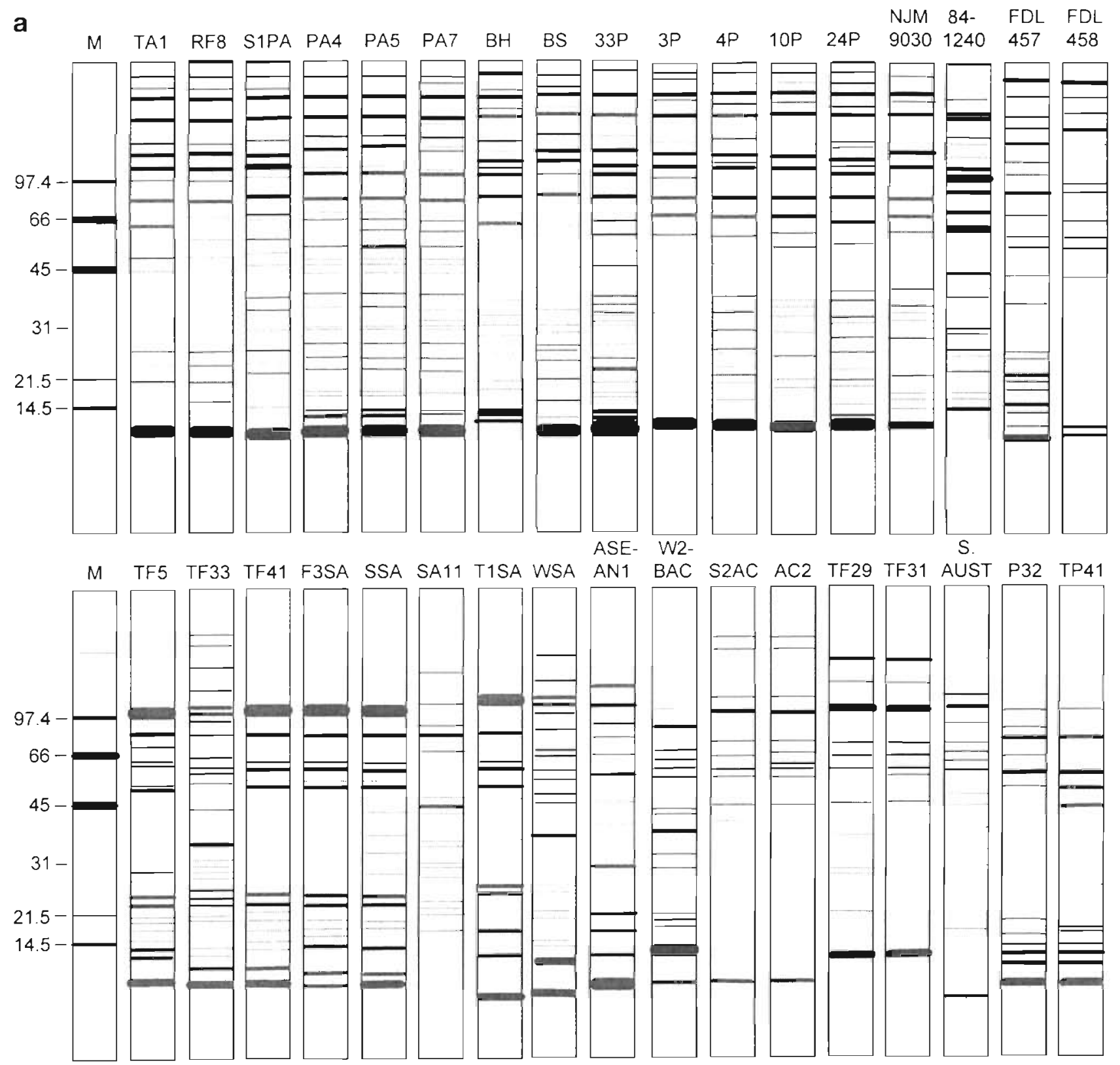

for all lectins tested except LEA. Similar banding patterns were obtained with GMA, BS-1, UEA-1 and AHA among the saprophytes.

\section{Polyclonal antisera}

Western blot analyses showing the response of the 3 polyclonal antisera against fungal extracts are presented in Fig. 5. The anti-saprophyte $(\alpha$ F3SA) and antiAphanomyces invadans ( $\alpha$ PA7) serum showed a high degree of cross-reactivity with all isolates tested, with both antisera recognising similar bands on a given
Fig. 2. (a) Pictorial representation of silver-stained SDS-PAGE gels $(4-20 \%)$ of selected isolates. (b) Silverstained electroeluted $10 \mathrm{kDa}$ band (on $4-20 \%$ SDSPAGE gel)

\section{b}

$97.4=$

$66.2-$

$45.0-$

$31.0-$

$21.5-$

$14.4-$ 


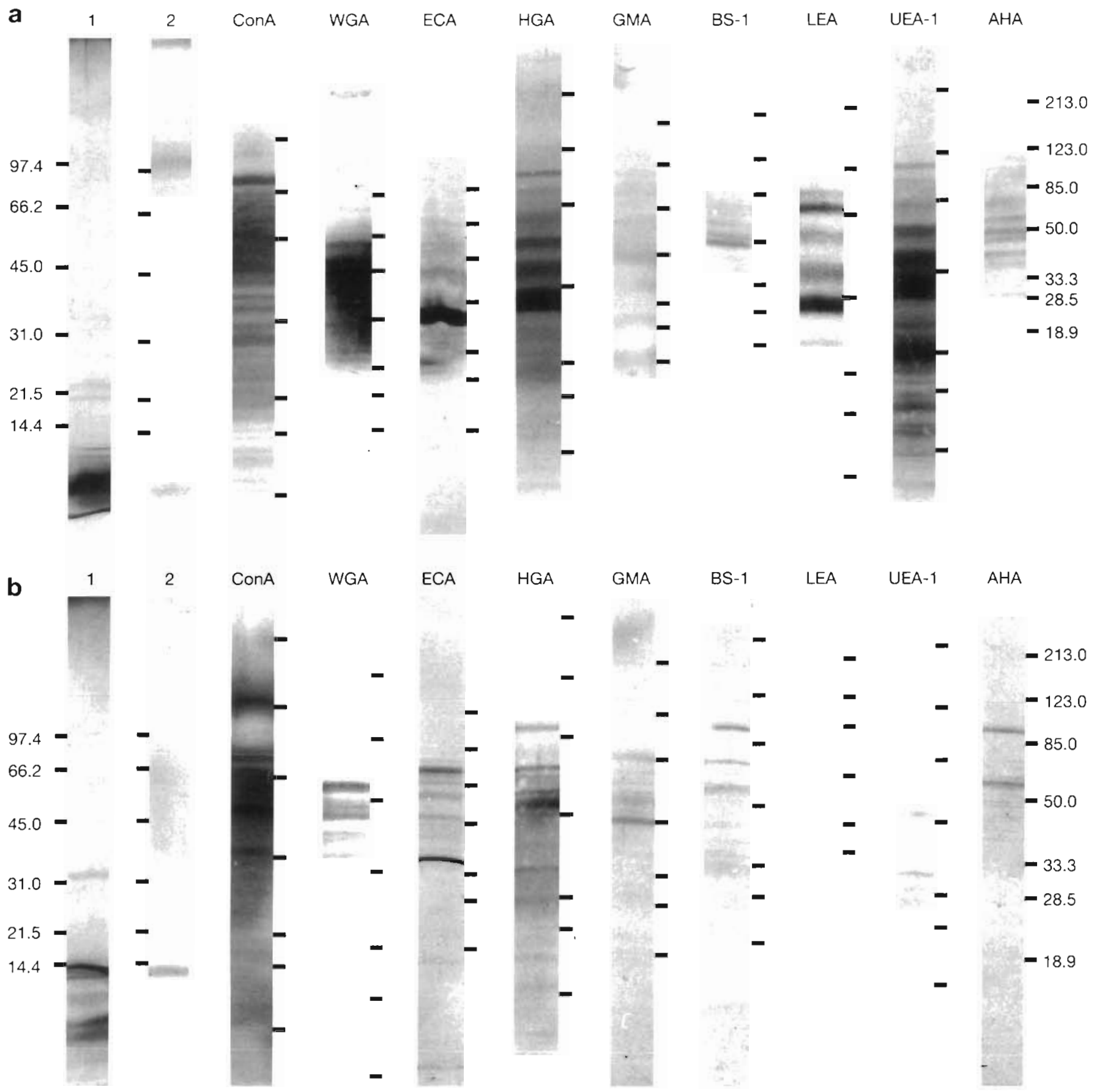

Fig. 3. Polysaccharide banding patterns of SDS-PAGE gels (4-20\%) (a) Aphanomyces invadans isolate PA7 and (b) saprophytic Aphanomyces isolate F3SA. Lanes: (1) proteinase K-treated silver-stained gel; (2) Schiff's-stained gel; (3 to 11) Western blots stained with various lectins. BioRad low-range markers are indicated on the left of Lanes 1 and 2 and BioRad broad-range markers are indicated on the right of lanes 3 to 11

isolate (Fig. 5a, b). However, the $\alpha$ F3SA serum recognised a band at $45 \mathrm{kDa}$ on PA7 and a band at $42 \mathrm{kDa}$ on F3SA which the o.PA7 serum only faintly recognised. There was also a substantial amount of staining of low molecular weight material in the F3SA extract by the $\alpha F 3 S A$ serum which was not recognised by the $\alpha \mathrm{PA} 7$ serum. Both the $\alpha F 3 S A$ and $\alpha$ PAF sera recognised the $10 \mathrm{kDa}$ band of PA7 and were also able to recognise this band in the pathogenic MG isolate NJM9030 (RSD isolates were not tested with these antisera). 
Fig. 4. Western blots of various isolates of Aphanomyces invadans (Lanes 1 to 6) and RSD-Aphanomyces (Lanes 7 and 8) stained using (a) HGA and (b) ECA. Lanes: (1) RF6; (2) G2PA; (3) PA7; (4) $\mathrm{BH}$; (5) 36/1P; (6) $10 \mathrm{D}_{\text {; }}$ (7) $4 \mathrm{P}$; and (8) $24 \mathrm{P}$
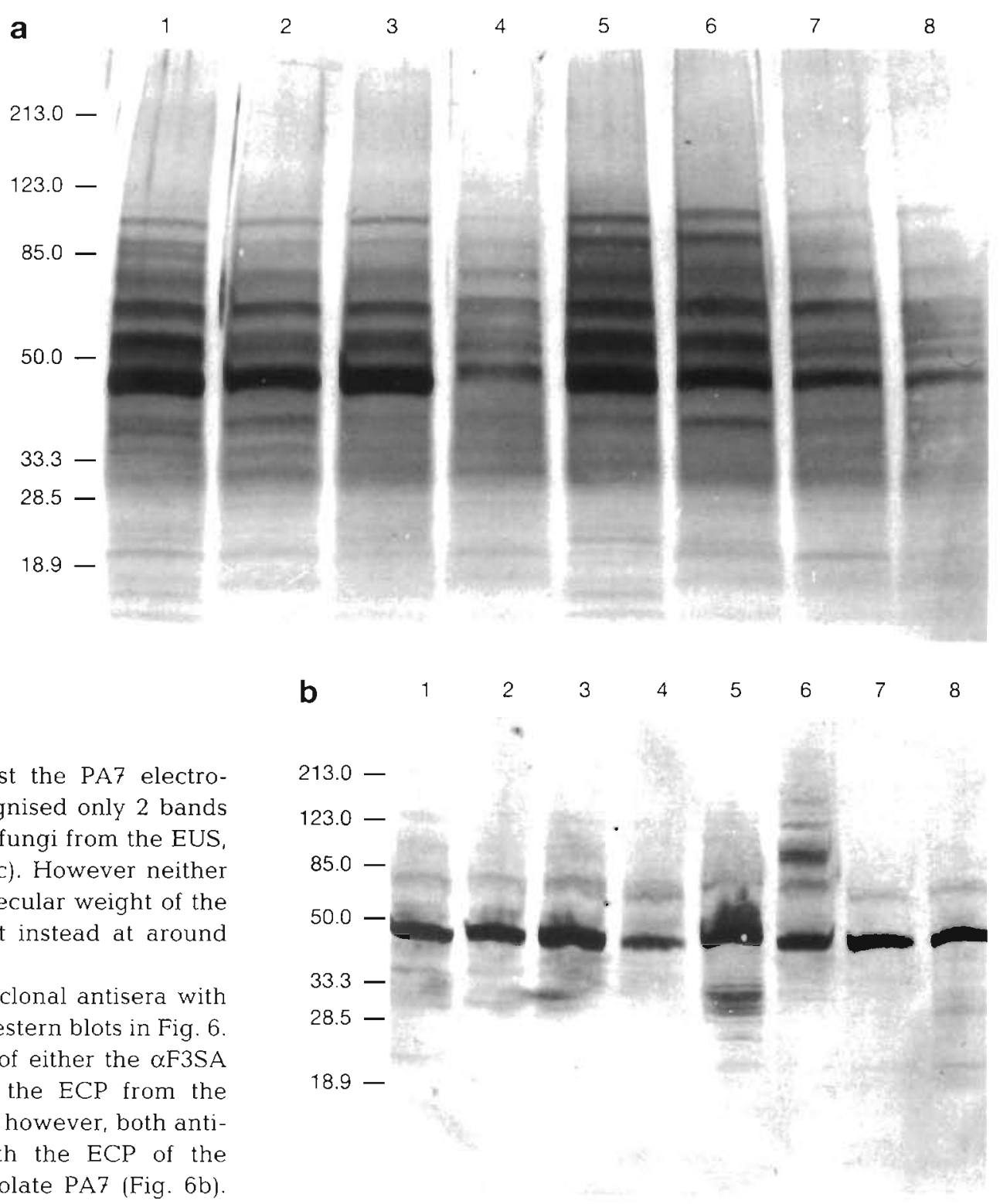

Antiserum raised against the PA7 electroeluted band ( $\alpha$ band) recognised only 2 bands found solely in extracts of fungi from the EUS, RSD or MG group (Fig, 5c). However neither band appeared at the molecular weight of the original $10 \mathrm{kDa}$ band, but instead at around $50 \mathrm{kDa}$.

The reaction of the polyclonal antisera with fungal ECP is shown by Western blots in Fig. 6 . There was little response of either the $\alpha$ F3SA or the $\alpha$ PAf serum with the ECP from the saprophyte F3SA (Fig. 6a); however, both antisera reacted strongly with the ECP of the Aphanomyces invadans isolate PA7 (Fig. 6b). Six major bands were observed at about 20, 35 , $45,50,60$ and $85 \mathrm{kDa}$ in the PA7 ECP. Anti-PA7 band serum did not react with ECP of either PA7 or F3SA (Fig 6c).

\section{Histochemical analysis}

Fungal hyphae in tissues of snakehead fish infected with Aphanomyces invadans isolate TA1 were positively labelled with both $\alpha$ F3SA and $\alpha$ PA7 when the secondary antibody was conjugated with either HRP (Fig. 7a, b respectively) or FITC (Fig. 8a, b), with the $\alpha$ F3SA serum eliciting the stronger response of the two. Hyphae were only very faintly labelled with $\alpha$ PA7 band serum (Figs. $7 \mathrm{c} \& 8 \mathrm{c}$ ), while no reaction occurred with the negative control (Figs. $7 d \& 8 d$ ). 

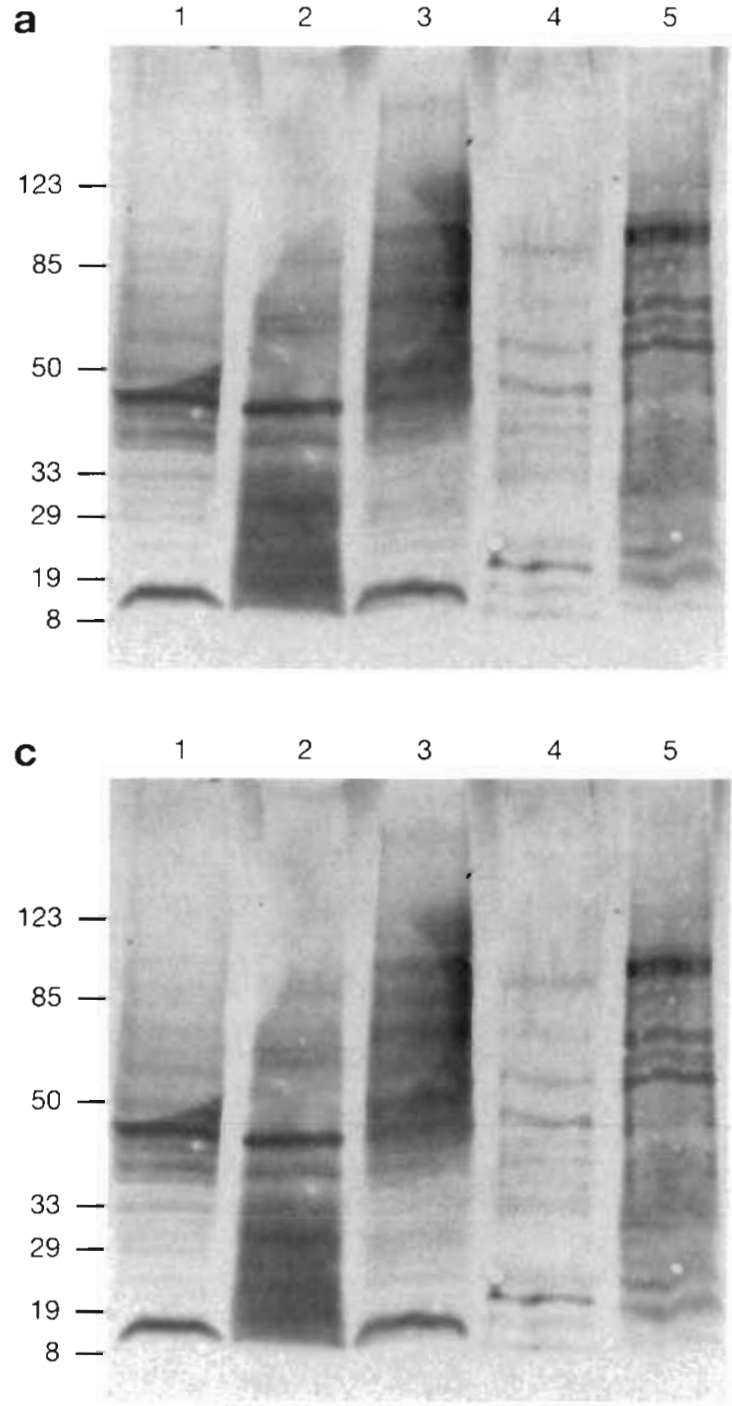

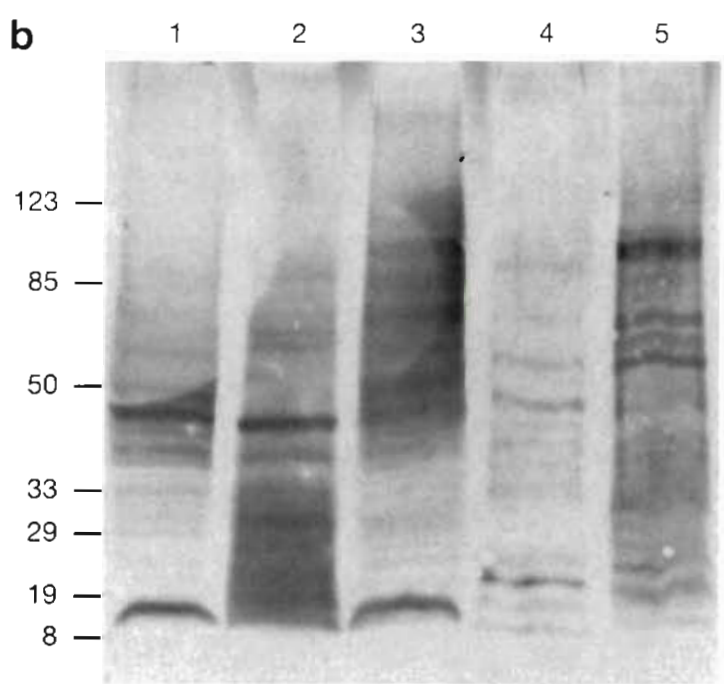

Fig. 5. Western blot analyses showing the response of various polyclonal antisera with different fungal extracts. (a) Rabbit anti-saprophyte $(\alpha \mathrm{F} 3 \mathrm{SA})$, (b) rabbit anti-Aphanomyces invadans ( $\alpha$ PA7), and (c) rabbit anti-PA7 electroeluted band (aband). Lanes: (1) extract from $A$ invadans strain PA7; (2) extract from saprophytic Aphanomyces F3SA; (3) extract from MG strain NJM9030; (4) extract from Aphanomyces astaci strain FDL458; and (5) extract from UM strain 84-1240 a

b

$123-$

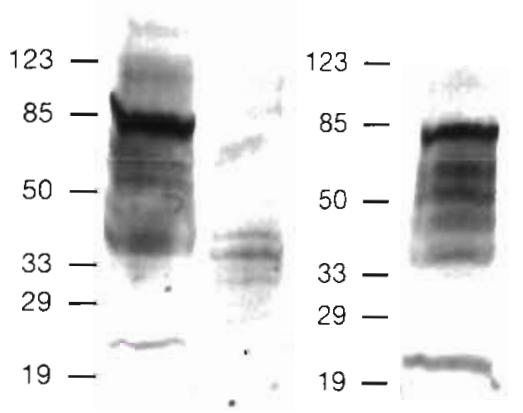

$85-$

$50-$

$33-$

$29-$

$19-$

Fig. 6. Reaction of polyclonal antisera with fungal extracellular products (ECP) by Western blot analysis. (a) Rabbit anti-saprophyte $(\alpha \mathrm{F} 3 \mathrm{SA})$; (b) rabbit anti-Aphanomyces invadans $(\alpha \mathrm{PA} 7)$, and $(\mathrm{c})$ rabbit anti-PA7 electroeluted band ( $\alpha$ band). Lanes: (1) ECP from $A$. invadans strain PA7; and (2) ECP from saprophytic Aphanomyces F3SA 
Fig. 7. Reaction of rabbit polyclonal antisera with tissues from snakehead fish infected with Aphanomyces invadans (strain TA1) by immunohistochemistry. Plates show the reactions obtained with (a) rabbit anti-saprophyte $(\alpha F 3 S A)$, (b) rabbit anti-A. invadans ( $\alpha$ PA 7 ), (c) rabbit anti-PA7 electroeluted band (aband), and (d) negative control (normal rabbit serum). Magnification is 100 -fold
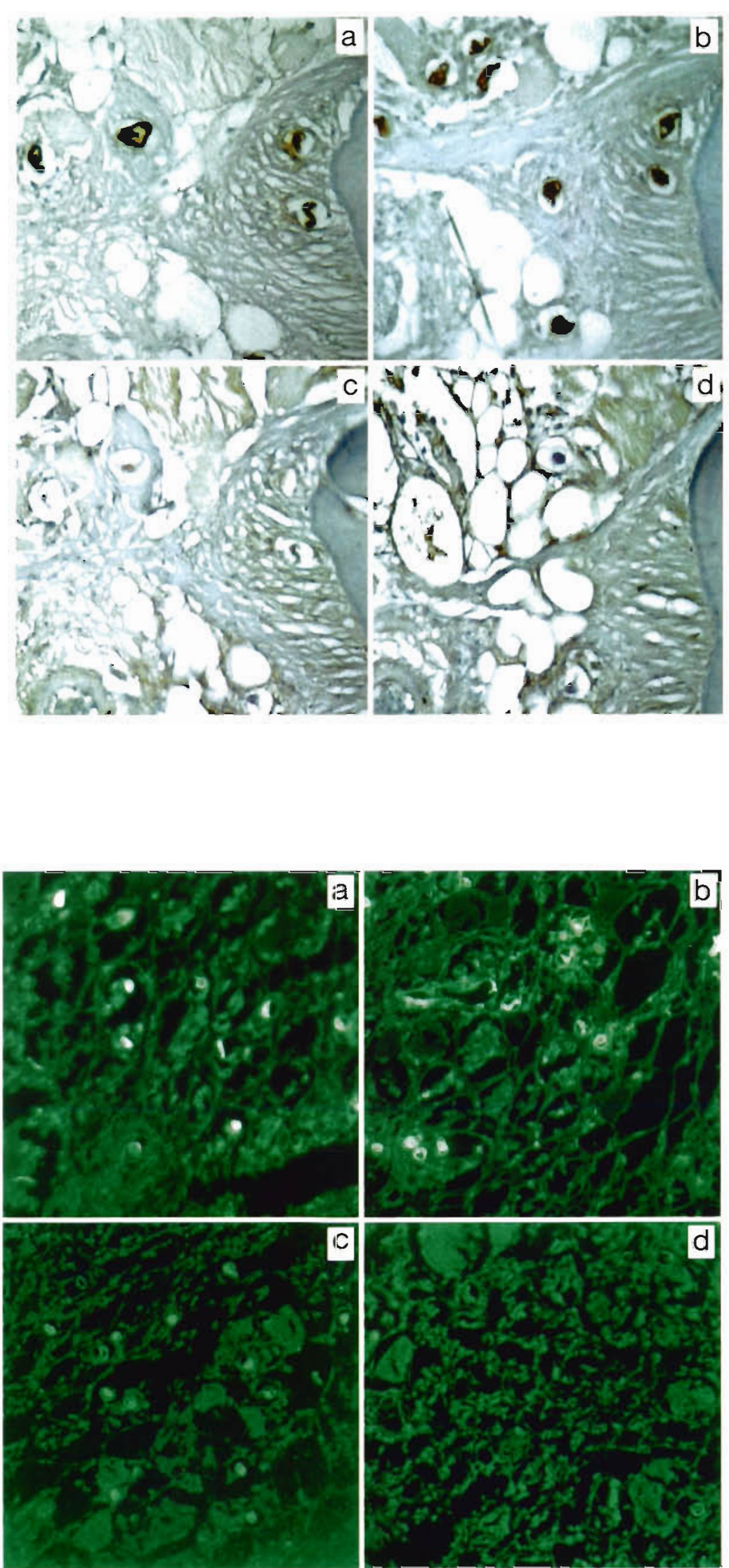

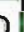

Fig. 8. Reaction of rabbit polyclonal antisera with tissues infected with Aphanomyces invadans (strain TA1) by the indirect fluorescent antibody technique. Plates show the reac. tions obtained with (a) rabbit anti-saprophyte $(\alpha \mathrm{F} 3 \mathrm{SA}),(b)$ rabbit anti-A. invadans ( $\alpha \mathrm{PA} 7)$, (c) rabbit anti-PA7 electroeluted band (aband), and (d) negative control (normal rabbit serum). Magnification is 100 -fold 
indicate that the EUS, RSD and MG isolates form a homogenous group and are probably conspecific ( $\mathrm{J}$ Lilley et al unpubl.). As Aphanomyces piscicida, the name used to describe $\mathrm{MG}$ isolates, is not valid under the International Code for Botanical Nomenclature (Korf 1995), the name Aphanomyces invadans will therefore be used here to describe all the EUS, RSD and MG fungal pathogens.

Protein profiles, as revealed by Coomassie Brilliant Blue $\mathrm{R}$ and silver staining, were complex and difficult to reproduce consistently. However, it was possible to identify specific bands that could act as taxonomic markers for Aphanomyces invadans, although they differed between the 2 stains. It may be the case that the 3 bands identified in the Coomassie Brilliant Blue $R$ stained gels of $A$. invadans equate with the 3 major bands in EUS and RSD samples that are shown between the 43 and $87 \mathrm{kDa}$ reference markers in Callinan et al. (1995). The latter workers, however, grew their fungi for $15 \mathrm{~d}$ at $30^{\circ} \mathrm{C}$; whereas, in the present study, mycelium was grown from zoospores for a maximum of $3 \mathrm{~d}$ at $22^{\circ} \mathrm{C}$ to ensure a high proportion of protein-rich growing tips. This difference in the age of the samples would affect the biochemical composition of the cells, and thus may be reflected in the different SDS-PAGE profiles. This is also an important consideration when comparing different fungi of greatly varying growth rates. In the present study, growth times were adjusted to between 1 to $3 \mathrm{~d}$ so as to produce similar weight yields for each fungus. Despite this adjustment, the slower-growing $A$. invadans isolates still showed more intense coloration than the other fungi with both Coomassie Brilliant Blue R and silver stain.

Silver stain reacts with carbohydrate as well as protein, and in order to highlight the carbohydrate bands, an initial protein digest treatment was performed on each sample. This treatment revealed very few bands, suggesting that the majority of bands in non-treated silver-stained samples were associated with protein. Proteinaceous glycoconjugates would have been broken down by the proteinase $\mathrm{K}$ digest and the resulting products may constitute at least part of the low molecular weight bands observed in the samples. Sadowski \& Powell (1990) used silver methenamine to show that the plasma membranes of Aphanomyces euteiches zoospores were rich in glycoproteins; thus, the membranes may be the main source of this material in the mycelial extracts tested here. Schiff's, a general carbohydrate stain, also showed few bands, but these did reveal differences between Aphanomyces invadans and the other fungi.

Western blots using lectins gave a more sensitive analysis of the specific carbohydrate moieties in each sample and provided a robust technique for distinguishing Aphanomyces invadans samples from other fungi. Only one lectin (ECA) showed any differences between the $A$. invadans isolates and may provide a useful means of strain-typing. Some lectins with different carbohydrate specificities revealed similar banding patterns, which may be explained in that each of the bands visualized were composed of complex polysaccharides with different residues accessible to the various lectins.

Other workers have used lectin-binding properties to characterise the surface components of Oomycete zoospores, cysts and germlings (Burr \& Beakes 1994). Con A-binding material (mannose and glucose) was shown to be associated with the glycocalyx of the propagules of a variety of Oomycete species (Burr \& Beakes 1994). The high reactivity of Con A with all the fungi tested here suggests that there are significant amounts of these saccharides in the mycelium of saprolegniaceous species as well.

The polyclonal antisera, $\alpha$ F3SA and $\alpha$ PA7, showed a great lack of specificity, with $\alpha F 3 S A$ reacting more strongly with PA7 than homologous antiserum. These antisera also reacted strongly with bands from Achlya and Saprolegnia samples (data not shown). This is consistent with the results of Bullis et al. (1990, 1996), which showed that mouse anti-Saprolegnia parasitica sera even cross-reacted with some non-Oomycete fungi. However, Western blots exposed to these antisera gave simple banding patterns that were consistent for Aphanomyces invadans isolates and distinct from other Aphanomyces spp. tested. The $10 \mathrm{kDa}$ band was clearly identified on $A$. invadans samples by both the $\alpha F 3 S A$ and the $\alpha$ PA 7 rabbit antisera. This band was also identified by artificially and naturally infected snakehead fish sera (Thompson et al. 1997). Thus, the $10 \mathrm{kDa}$ band has been shown to be immunogenic in fish and rabbits. However, the antiserum prepared by injecting the electroeluted $10 \mathrm{kDa}$ band into rabbits did not recognise the $10 \mathrm{kDa}$ band by Western blot. Instead, 2 bands at around $50 \mathrm{kDa}$ were recognised on A. invadans samples. These bands were also faintly visible on silver-stained gels of the electroeluted $10 \mathrm{kDa}$ band (Fig. 2b), and their appearance may be due to conformational changes to the $10 \mathrm{kDa}$ band as a result of electroelution. Nonetheless, these bands were specific to $A$. invadans as $\alpha$ band serum did not cross-react with other fungus samples.

The serum raised against mycelium extract from a saprophytic Aphanomyces ( $\alpha \mathrm{F} 3 \mathrm{SA}$ ) did not recognise ECP secreted by homologous fungus but did recognise the same secreted products from PA7 as o.PA7. This suggests that $A$. invadans isolate PA 7 secreted greater quantities of ECP than the saprophyte F3SA, which may represent the release of proteolytic enzymes relevant in the pathogenesis of $A$. invadans. The molecular weights of the bands in the ECP recognised by the antisera did 
not directly correspond to bands found in the mycelium extract. However, the antisera were raised against mycelium extract and therefore bands recognised in the ECP should correspond to components found in the mycelium extract. If this is the case, the difference in molecular weight of the bands revealed between the 2 samples may be explained by ECP components being altered in some way, such as being cleaved on secretion. As the $\alpha$ F3SA serum recognised the PA7 ECP, this illustrates the non-specific nature of the antisera. However, the lack of any reaction with the oband serum suggests that the electroeluted band is not secreted into the ECP or was lost on dialysis during sample preparation.

The rabbit antisera proved an effective diagnostic tool for identifying fungal hyphae in fish tissue, particularly by IFAT, and compares favourably with conventional Grocott staining in terms of ease of use. It would be interesting to use this technique on sections of UMaffected fish tissue to compare reactivity of the invasive fungus involved in that disease with that of Aphanomyces invadans. A UM Aphanomyces isolate was shown here to have very different protein and carbohydrate profiles from $A$. invadans, but it is possible that this is not actually the invasive pathogen involved in that disease (Lilley \& Roberts 1997). Lectins were used on sections of infected fish tissue in an attempt to obtain a more specific stain for $A$. invadans. This technique has been used for other fish diseases (Marin de Mateo et al. 1993), but the lectins tested here gave no discernible reactivity. Raising monoclonal antibodies against $A$. invadans hyphal material would provide a means of developing a more specific probe for use in the immunohistochemical diagnosis of EUS.

Acknowledgements. J.H.L. and K.D.T were funded by the Overseas Development Administration of the United Kingdom. We thank the following for the provision of fungal isolates: Dr L. G. Willoughby, Dr S. Chinabut, Dr D. Bastiawan, Dr J. O. Paclibare, Dr G. C. Fraser, Dr A. Thomas, Professor K. Hatai, Professor E. J. Noga, Dr D. J. Alderman and Miss W. Valairatana.

\section{LITERATURE CITED}

Adams A, Marin de Mateo M (1994) Immunohistochemical detection of fish pathogens. In: Stolen JS, Fletcher TC, Rowley AF, Zelikoff JT, Kaattari SL, Smith SA (eds) Techniques in fish immunology No. 3. SOS Publications, Fair Haven, NJ, p 133-143

Alderman DJ (1993) Crayfish plague in Britain, the first twelve years. Freshwat Crayfish 9:266-272

Bruno DW, Stamps DJ (1987) Saprolegniasis of Atlantic salmon, Salmo salar L., fry. J Fish Dis 10:513-517

Bullis RA, Noga EJ, Levy MG (1990) Immunological relationship of the fish-pathogenic oomycete Saprolegnia parasitica to other oomycetes and unrelated fungi. J Aquat Anim Health 2:223-227
Bullis RA, Noga EJ, Levy MG (1996) Production and preliminary characterization of monoclonal antibodies to Saprolegnia parasitica. Mycol Res 100:489-494

Burr AW, Beakes GW (1994) Characterization of zoospore and cyst surface structure in saprophytic and fish pathogenic Saprolegnia species (oomycete fungal protists). Protoplasma 181:142-163

Callinan RB, Paclibare JO, Bondad-Reantaso MG, Chin JC, Gogolewski RP (1995) Aphanomyces species associated with epizootic ulcerative syndrome (EUS) in the Philippines and red spot disease (RSD) in Australia: preliminary comparative studies. Dis Aquat Org 21:233-238

Chen W, Hoy JW, Schneider RW (1991) Comparisons of soluble proteins and isozymes for seven Pythium species and applications of the biochemical data to Pythium systematics. Mycol Res 95:548-555

Dykstra MJ, Levine JF, Noga EJ, Hawkins JH, Gerdes P, Hargis WH Jr, Grier HJ, Te Strake D (1989) Ulcerative mycosis: a serious menhaden disease of southeastern coastal fisheries of the United States. J Fish Dis 12:175-178

Hatai K (1980) Studies on the pathogenic agents of saprolegniasis in fresh water fishes. Spec Rep No. 8 Nagasaki Prefectural Institute of Fisheries

Index of fungi (1997) David JC, Kirk PM (eds) IMI: CAB International, Wallingford 6(13):706

Korf RP (1995) Authors, reviewers, and editors of articles proposing new names: a few guidelines. Mycotaxon 54 $413-418$

Laemmli UK (1970) Cleavage of structural proteins during assembly of the head of bacteriophage T4. Nature 227 : $680-685$

Latorre BA, Perez GF, Wilcox WF, Torres R (1995) Comparative protein electrophoretic and isoenzymic patterns of Phytophthora cryptogea isolates from Chilean kiwifruit and North American deciduous fruits. Plant Dis 79(7):703-708

Lilley JH, Roberts RJ (1997) Pathogenicity and culture studies comparing the Aphanomyces involved in epizootic ulcerative syndrome (EUS) with other similar fungi. J Fish Dis 20:101-110

Marin de Mateo M, Adams A, Richards RH, Castagnaro M, Hedrick RP (1993) Monoclonal antibody and lectin probes recognize developmental and sporogonic stages of PKX, the causative agent of proliferative kidney disease in European and North American salmonid fish. Dis Aquat Org 15:23-29

Neelam B, Thompson KD, Price NC, Tatner MF, Adams A, Ellis AE, Stevens L (1995) Development of monoclonal antibodies to iron-regulated outer membrane proteins and lipopolysaccharide of Aeromonas salmonicida. Dis Aquat Org 21:201-208

Sadowski LA, Powell MJ (1990) Cytochemical detection of polysaccharides in zoospores of Aphanomyces euteiches. Can J Bot 68:1379-1388

Thompson KD, Lilley JH, Adams A (1997) The antibody response of snakehead, Channa striata Bloch, to Aphano myces invaderis. Fish Shelltish Immunol 7:349-353

Willoughby LG, Roberts RJ (1994) Loss and recovery of zoospore motility in an isolate of Aphanomyces from a diseased fish. Mycol Res 98:1463-1464

Willoughby LG, Roberts RJ, Chinabut S (1995) Aphanomyces invaderis sp. nov., the fungal pathogen of freshwater tropical fish affected by epizootic ulcerative syndrome. J Fish Dis 18:273-275

Wood SE (1988) The monitoring and identification of Saprolegnia parasitica and its infection of salmonid fish. $\mathrm{PhD}$ dissertation, University of Newcastle upon Tyne 


\title{
Erratum
}

\section{Characterization of Aphanomyces invadans by electrophoretic and Western blot analysis}

\author{
J. H. Lilley, K. D. Thompson, A. Adams
}

Diseases of Aquatic Organisms 30: 187-197, 1997

- Fig. 5 on page 194 was incorrect - the same gel was shown three times. The corrected figure and its caption appear here.
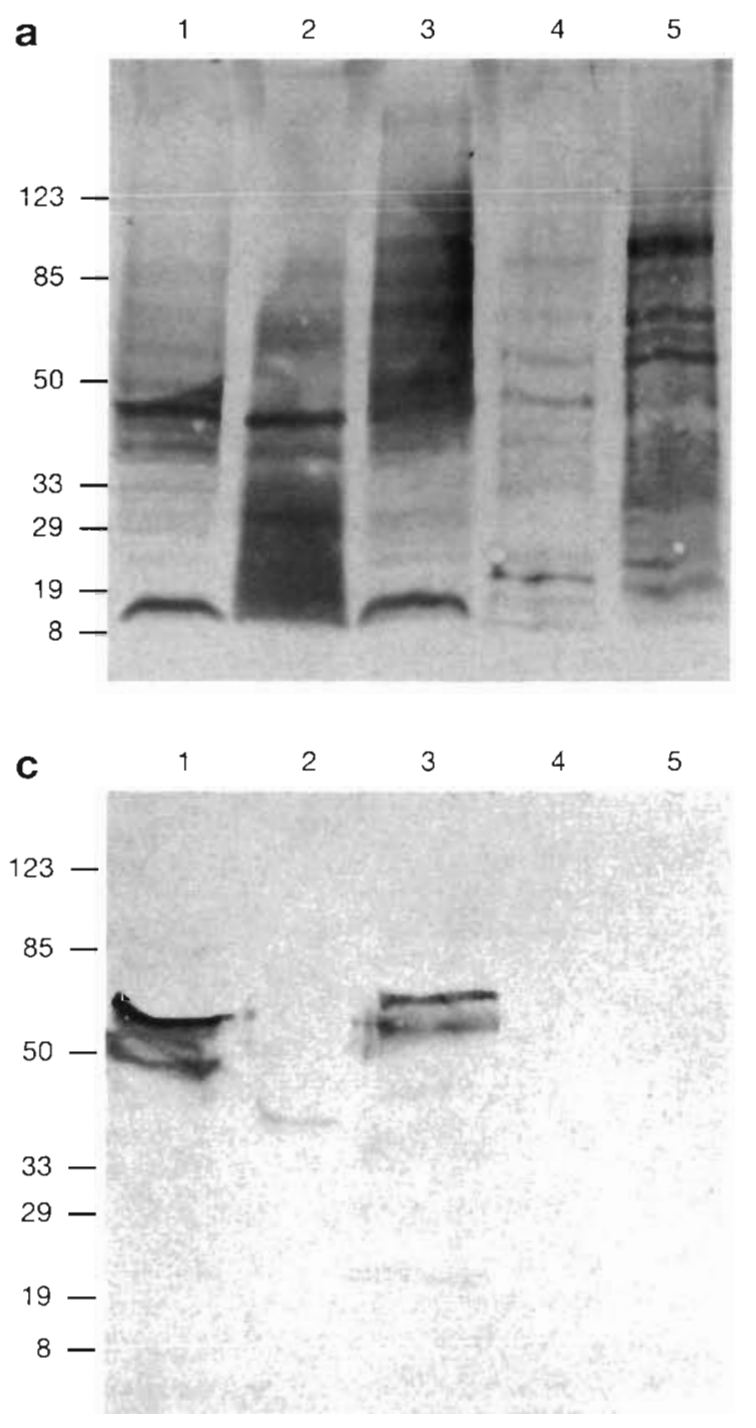

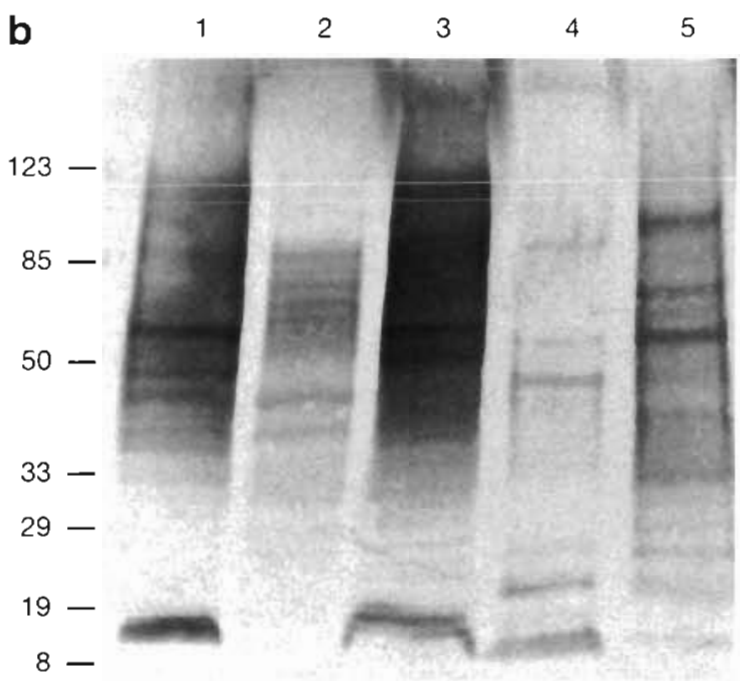

Fig. 5. Western blot analyses showing the response of various polyclonal antisera with different fungal extracts. (a) Rabbit anti-saprophyte $(\alpha \mathrm{F} 3 \mathrm{SA}),(\mathrm{b})$ rabbit anti-Aphanomyces invadans ( $\alpha$ PA7), and (c) rabbit anti-PA7 electroeluted band (aband). Lanes: (1) extract from $A$ invadans strain $P A 7$; (2) extract from saprophytic Aphanomyces F3SA; (3) extract from MG strain NJM9030; (4) extract from Aphanomyces astaci strain FDL458; and (5) extract from UM strain 84-1240 